\title{
Solubilização de fosfato por microrganismos rizosféricos de genótipos de Guandu cultivados em diferentes classes de solo
}

\section{Phosphate solubilization by microorganisms from the rhizosphere of Pigeonpea genotypes grown in different soil classes}

\author{
Edson Luiz Souchie ${ }^{1 *}$; Antonio Carlos de Souza Abboud ${ }^{2}$
}

Resumo

\begin{abstract}
Microrganismos solubilizadores de fosfato foram isolados da rizosfera de seis genótipos de guandu (Cajanus cajan L. Millsp.) cultivados em vasos contendo solo pertencente a seis diferentes classes: Luvissolo, Cambissolo, Cambissolo Eutrófico, Argissolo Vermelho Amarelo, Neossolo Regolítico, Vertissolo, todos da região nordeste brasileira. Fungos foram obtidos em maior número (85) que bactérias (46). Um maior número (11) de fungos foi proveniente do Cambissolo Eutrófico cultivado com o genótipo D1-Type; um total de 24 isolados de bactéria foi proveniente do Neossolo Regolítico cultivado com os genótipos Moreilândia (14) e D1-Type (10), isolando-se um número bem menor (2) nos demais solos. A solubilização de fosfato de Araxá por 131 isolados foi quantificada em meio líquido contendo $2000 \mathrm{mg} \mathrm{L}$ ${ }^{1}$ de meio líquido. A maioria dos fungos baixou o $\mathrm{pH}$ do meio de 6,5 para valores entre 2,0 e 4,0 , enquanto que, para as bactérias, a variação foi de 4,0 e 6,5. As médias de P solubilizado foram de 122 e $15 \mathrm{mg} \mathrm{L}^{-1}$ para os fungos e bactérias, respectivamente. Identificaram-se 15 isolados (14 sendo Aspergillus e 1 Penicillium) com maior habilidade em solubilizar $\mathrm{P}$. O teor de $\mathrm{P}$ solubilizado e o número de isolados solubilizadores dependeram do tipo de solo e do genótipo de guandu. Estudos mais detalhados são necessários para melhor elucidar essas interações.
\end{abstract}

Palavras-chave: Cajanus cajan, microrganismos solubilizadores de fosfato, fosfato natural

\begin{abstract}
P-solubilizing microorganisms were isolated from the rhizosphere of six genotypes of pigeonpea (Cajanus cajan L. Millsp.) grown in pots containing soil from six classes: "Luvissolo", "Cambissolo", "Cambissolo Eutrófico", "Argissolo Vermelho Amarelo", "Neossolo Regolítico" and "Vertissolo". All soils came from the Northeast region of Brazil. Eighty-five isolates were fungi and 46 bacteria. Eleven fungal isolates came from "Cambisssolo Eutrófico" cultivated with the genotype D1-Type; fourteen and ten isolates of bacteria came from "Neossolo Regolítico" cultivated with genotype Moreilândia and D1-Type, respectively. For the other soil classes, the number of bacteria was much lower (2 isolates). In vitro phosphate solubilization by 131 microorganisms was performed after incubation in liquid medium containing $2000 \mathrm{mg} \mathrm{L}^{-1}$ of "Araxá" apatite. The majority of fungal isolates decreased the $\mathrm{pH}$ to the range from 2.0 to 4.0 and bacteria from 4.0 to 6.5. Soluble P averaged 122 and $15 \mathrm{mg} \mathrm{P} \mathrm{L}^{-1}$ for fungi and bacteria, respectively. Fifteen fungi isolates (14 Aspergillus and 1 Penicillium) more able in solubilizing P in liquid medium were chosen for identification. The amount of solubilized $\mathrm{P}$ and the number of P-solubilizing isolates depended on the soil type and pigeonpea genotype. Further studies should be performed to elucidate these interactions.
\end{abstract}

Key words: Cajanus cajan, P-solubilizing microorganisms, natural phosphate

1 Lic. Ciências Agrícolas, Prof. Dr. Centro Federal de Educação Tecnológica, Rio Verde, GO. E-mail: esouchie@yahoo.com.br

2 Eng. Agrônomo, Prof. Dr. UFRRJ / IA - Departamento de Fitotecnia, Seropédica, RJ, E-mail: abboud@ufrrj.br

* Autor para correspondência

Recebido para publicação 08/05/06 Aprovado em 15/09/06 


\section{Introdução}

Uma parcela importante da comunidade microbiana edáfica possui a habilidade de mineralizar fosfatos orgânicos e solubilizar fosfatos inorgânicos, permitindo a liberação de fósforo assimilável pelas plantas (SILVA FILHO, 1998). Tais microrganismos apresentam potencial de utilização como inoculante, já que podem maximizar o desenvolvimento vegetal (SAHIN; ÇAKMAKÇI; KANTAR, 2004; SOUCHIE et al., 2005a).

Segundo Silva Filho (1998), a população de microrganismos solubilizadores de fosfatos (MSF) existentes nos solos está entre $10^{4}$ e $10^{7} \mathrm{~g}^{-1}$ de solo, variando conforme o local e o método de avaliação. Abboud (1986) observou populações de bactérias e fungos solubilizadores de fosfato da ordem de $10^{6} \mathrm{~g}^{-}$ ${ }^{1}$ de solo da rizosfera de diversas leguminosas, incluindo guandu (Cajanus cajan L. Millsp.). Para esta espécie, houve a maior ocorrência de fungos em relação a cinco outras espécies. Da mesma forma, Barroti e Nahas (2000) verificaram incremento da população de fungos solubilizadores de fosfato quando se associa guandu a fosfato de Araxá. Carneiro et al. (2004) detectaram aumento das populações de bactérias e fungos solubilizadores em solo de Cerrado cultivado com guandu.

Otani, Ae e Tanaka (1996) estudando os tipos de ácidos orgânicos presentes nos exsudatos das raízes de guandu, determinaram que ácido malônico foi o principal componente, seguido de oxálico e piscídico. Estes ácidos orgânicos foram capazes de liberar $\mathrm{P}$ a partir de $\mathrm{FePO}_{4}$ e $\mathrm{AlPO}_{4}$ Sarapatka e Krskova (1997) relatam que a liberação de fosfatase ácida pelas raízes pode potencialmente liberar fósforo a partir da fração orgânica do solo. Neste sentido, Ascencio (1996) relata que a atividade da fosfatase ácida secretada pelas raízes de guandu aumentou sob condições de deficiência de P.

A solubilização de fosfato em meio sólido pode ser avaliada pela formação de um halo transparente ao redor da colônia, em contraste com o meio opaco (KANG et al., 2002) ou pela solubilização de fosfato em meio líquido adicionado de fontes insolúveis desse elemento (KUMAR; BEHL; NARULA, 2001; SOUCHIE et al., 2005b).

De acordo com Kucey (1983) e Nahas, Centurion e Assis (1994) a população de microrganismos solubilizadores de fosfato e sua capacidade de solubilização estão intimamente relacionadas ao tipo e ao manejo do solo. Kirchner, Wollum e King (1993) sugerem que as diferenças relacionadas à diversidade de bactérias no solo podem ser simplesmente devido ao tipo de planta existente.

Com o intuito de diminuir o uso e otimizar o aproveitamento de fertilizantes fosfatados solúveis na agricultura, justificam-se estudos enfocados no isolamento e quantificação da capacidade de solubilização de fosfatos insolúveis por MSF visando ao seu uso futuro na forma de inoculantes.

Este trabalho objetivou isolar MSF do rizoplano mais rizosfera de seis genótipos de guandu, crescidos em seis classes de solos provenientes da região nordeste brasileira e quantificar sua capacidade de solubilização de fosfato de Araxá em meio líquido.

\section{Material e Métodos}

Obtenção dos isolados

O isolamento de bactérias e fungos solubilizadores de fosfato foi feito a partir do rizoplano mais rizosfera de seis genótipos de guandu, utilizando-se os meios GL ( glicose $=10 \mathrm{~g}$; extrato de levedura $=0,5 \mathrm{~g}$ e agar $\left.=15 \mathrm{~g} \mathrm{~L}^{-1}\right)$ e GELP $($ glicose $=10 \mathrm{~g}$; extrato de levedura $=0,5 \mathrm{~g}$; peptona $=5 \mathrm{~g}$; extrato de solo $=100 \mathrm{~mL}$; sais de base $=2 \mathrm{~mL}$ e agar $\left.=15 \mathrm{~g} \mathrm{~L}^{-1}\right)$ descritos por Sylvester-Bradley et al. (1982).

Os genótipos de guandu e suas procedências foram: PPPI-1264 do IAPAR; UW-10, Moreilândia e D1-Type da Embrapa Semi-Árido; "CV208”, trazido de Portugal e "Seropédica", material genético coletado no município de Seropédica, RJ. As demais informações de cada genótipo são apresentadas na Tabela 1. 
Tabela 1. Características morfológicas dos genótipos de guandu (média de 10 plantas) utilizados neste estudo ${ }^{1}$

\begin{tabular}{cccccc}
\hline Genótipo & $\begin{array}{c}\text { No de vagens / } \\
\text { cacho }\end{array}$ & $\begin{array}{c}\mathbf{N}^{\mathbf{0}} \text { de vagens / } \\
\text { planta }\end{array}$ & $\begin{array}{c}\text { Peso de 100 } \\
\text { sementes (g) }\end{array}$ & $\begin{array}{c}\text { Dias até a } \\
\text { floração }\end{array}$ & $\begin{array}{c}\text { Altura no início } \\
\text { da floração (cm) }\end{array}$ \\
\hline CV208 & 6,0 & 240 & 8,2 & 77 & 68,5 \\
UW - 10 & 4,7 & 27,8 & 9,3 & 185 & 136,5 \\
D1 - Type & 3,4 & 93,8 & 7,8 & 225 & 80,7 \\
Seropédica & 5,3 & 2077,6 & 10,7 & 210 & 172,3 \\
PPPI-1264 & 3,1 & 458,8 & 14,6 & 220 & 193,4 \\
Moreilândia & 5,8 & 846,8 & 15,0 & 240 & 189,7 \\
\hline
\end{tabular}

${ }^{1}$ Caracterização realizada através do cultivo dos genótipos no campo experimental da Universidade Federal Rural do Rio de Janeiro, Seropédica - RJ.

As amostras de solo usadas para compor o substrato foram obtidas de diferentes locais da região nordeste brasileira e pertenciam a seis classes de solo: Cambissolo, Cambissolo Eutrófico, Neossolo Regolítico, Luvissolo, Vertissolo e Argissolo
Vermelho-Amarelo (Tabela 2). Essas amostras foram coletadas da camada superficial do solo, peneiradas (malha de $1 \mathrm{~cm}$ ), secadas ao ar e acondicionadas em sacos de papel à temperatura ambiente, ficando assim armazenadas por sete meses até seu uso.

Tabela 2. Características dos solos provenientes da região nordeste brasileira, utilizados para cultivo de guandu e isolamento de microrganismos solubilizadores de fosfato.

\begin{tabular}{|c|c|c|c|c|c|c|c|c|}
\hline \multirow[t]{2}{*}{$\begin{array}{l}\text { Classe de } \\
\text { Solo }\end{array}$} & Horizonte & $\begin{array}{c}\text { Argila } \\
\text { Total }\end{array}$ & $\begin{array}{c}\text { Argila } \\
\text { Natural }\end{array}$ & Areia & pH & \multirow{2}{*}{$\begin{array}{c}\text { Valor } \\
\text { T } \\
\text { cmol }_{\mathbf{c}} \mathbf{d m}^{-3}\end{array}$} & \multirow{2}{*}{$\begin{array}{c}\text { Valor } \\
\text { V } \\
\%\end{array}$} & \multirow{2}{*}{$\begin{array}{c}P^{*} \\
\mathrm{mg} \mathrm{kg}^{-1}\end{array}$} \\
\hline & $\mathbf{C m}$ & -------- & ---\%-----. & ------ & & & & \\
\hline Luvissolo & $\mathrm{AB}(12-18)$ & 22 & 18 & 57 & 7,4 & 9,0 & 91 & 1 \\
\hline Cambissolo & $\mathrm{A}(0-14)$ & 25 & 16 & 58 & 7,2 & 13,0 & 92 & 14 \\
\hline Cambissolo Eutrófico & BA (12-25) & 37 & 31 & 50 & 7,2 & 19,5 & 92 & 1 \\
\hline $\begin{array}{l}\text { Argissolo Vermelho- } \\
\text { Amarelo }\end{array}$ & A $(0-18)$ & 10 & 8 & 80 & 5,1 & 5,3 & 43 & 2 \\
\hline Neossolo Regolítico & A $(0-15)$ & 8 & 4 & 89 & 5,4 & 3,0 & 43 & 2 \\
\hline Vertissolo & $\mathrm{A}(0-15)$ & 70 & 54 & 8 & 8,1 & 58,4 & 100 & 109 \\
\hline
\end{tabular}

Fonte: Silva et al (1998)

$*$ P disponível $($ Extrator utilizado $=$ Mehlich I $)$

As plantas foram cultivadas em câmara de cultivo (50\% de umidade relativa, fotoperíodo de 13 horas, densidade de fluxo de radiação fotossinteticamente ativa de $503 \mu \mathrm{mol} / \mathrm{m}^{2} / \mathrm{s}$ e temperatura de 27 e $18{ }^{\circ} \mathrm{C}$ durante o dia e noite, respectivamente) copos plásticos de $400 \mathrm{~mL}$ (três plantas / copo), contendo a mistura areia + solo (1:8, baseado em peso) sendo irrigadas a cada dois dias.
O início do isolamento se deu aos 30 dias após a emergência das plântulas. Amostras de $1 \mathrm{~g}$ de solo do rizoplano mais rizosfera, juntamente com pedaços de radicelas, foram misturadas a $9 \mathrm{~mL}$ de solução salina (1\%) e diluídas sucessivamente até $10^{-7}$. De cada diluição foram transferidas alíquotas de $100 \mu \mathrm{L}$ para placas de Petri autoclavadas, acrescentandose logo em seguida os meios mantidos a temperatura 
de $45^{\circ} \mathrm{C}$ e misturados imediatamente (SYLVESTERBRADLEY et al., 1982). Como testemunha, foi feito plaqueamento com alíquotas de $100 \mu \mathrm{L}$ de solução salina esterilizada. Usaram-se triplicatas para cada diluição.

Após a incubação das placas por sete dias a 28 ${ }^{\circ} \mathrm{C}$, os MSF foram isolados a partir de sua identificação pela formação de um halo transparente ao redor da colônia, facilmente visível em contraste com o meio opaco, de acordo com Kang et al. (2002). Este halo indica a solubilização do precipitado de $\mathrm{CaHPO}_{4}$ contido no meio. Os organismos que formaram halo transparente foram repicados em placa de Petri contendo o mesmo meio em que foram originalmente obtidos. Posteriormente, foram armazenados em tubo de ensaio contendo meio sólido de mesma constituição e óleo mineral, a temperatura ambiente. Foi feita uma análise de ordenação bivariada dos organismos obtidos para se verificar padrões de agrupamento dos isolados quanto ao genótipo, classe de solo, tipo de organismo e diluição.

Quantificação in vitro da solubilização biológica de fosfato

Nesta etapa, foi feita a quantificação da solubilização de fosfato de rocha pelos isolados obtidos na etapa anterior ( 85 fungos e 46 bactérias), através de um teste em meio líquido (SYLVESTERBRADLEY et al., 1982) contendo fosfato de Araxá (14. $\mathrm{kg}^{-1}$ de P) na concentração de $2000 \mathrm{mg}$ de fosfato $\mathrm{L}^{-1}$. Foram determinados valores iniciais de $\mathrm{pH}$ e P solúvel. Após sete dias de incubação a $28^{\circ} \mathrm{C}$ procedeu-se a centrifugação (3.000 rpm por $15 \mathrm{~min}$ ), determinação do pH e a quantificação dos teores de P solúvel no sobrenadante (TEDESCO et al., 1995). Cada isolado foi incubado em duplicata sendo que o controle foi o meio de cultura mais a dose de fosfato de Araxá na ausência de microrganismo solubilizador.

\section{Identificação dos fungos}

Dentre os 85 isolados testados, 15 foram escolhidos para identificação por apresentarem maior potencial de solubilização de fosfato no meio líquido.

A identificação foi feita com base na sua morfologia, mediante a visualização de microcultivos em microscópio estereoscópico e ótico com aumentos de até 400 vezes. Cada microcultivo foi preparado a partir da deposição de um fino e pequeno quadrículo de meio de cultura sólido (GL) sobre uma lâmina previamente esterilizada. $\mathrm{O}$ meio foi em seguida inoculado e coberto por uma lamínula também esterilizada. $O$ conjunto foi colocado em uma placa de Petri, autoclavada, forrada com papel de filtro umedecido com água esterilizada. As lâminas foram então colocadas dentro desta placa e incubadas a $28^{\circ} \mathrm{C}$ durante cinco dias. Com base nos resultados obtidos nas visualizações e nas informações contidas em Singh et al. (1991), foi feito o enquadramento taxonômico destes fungos, em nível de gênero.

\section{Resultados e Discussão}

\section{Obtenção dos isolados}

Foram obtidos 85 isolados de fungo e 46 de bactéria. Um número desigual de isolados foi obtido nas diferentes combinações solo x genótipos e, em algumas delas, nenhum isolado foi obtido. Por exemplo, verificou-se que o maior número de isolados de fungos solubilizadores (9) foi proveniente do Cambissolo Eutrófico quando cultivado com o genótipo D1-Type (Tabela 2). Outro exemplo foi o maior número de isolados de bactéria proveniente do Neossolo Regolítico cultivado com os genótipos Moreilândia (14) e D1-Type (10) (Tabela 3). Comparando-se as classes de solo, observou-se um maior número de isolados de bactéria obtidos do Neossolo Regolítico (26), ao passo que nos demais solos o número foi menor e mesmo nulo no caso do Luvissolo (Tabela 3). Para os isolados de fungos solubilizadores de fosfato, o maior número (18) foi obtido do Argissolo Vermelho Amarelo e, da mesma forma como ocorreu para os isolados bacterianos, o Luvissolo foi o que possibilitou o menor número (8). Avaliando-se o número total de isolados fúngicos e bacterianos, constata-se que Argissolo Vermelho 
Amarelo (27) e Neossolo Regolítico (40) apresentaram o maior número. Tendo em vista que estas classes de solo foram as que apresentaram maior percentual de areia (Tabela 2), sua capacidade de retenção d'água foi menor. Consequentemente, as plantas estiveram mais susceptíveis a estresse hídrico, liberando uma maior quantidade de exsudatos radiculares, favorecendo ao aumento da população microbiana rizosférica solubilizadora de fosfatos. É sabido que, sob condições de estresse hídrico e nutricional, as plantas incrementam a liberação de exsudatos radiculares (LIEBERSBACH; STEINGROBE; CLAASSEN, 2004) que atraem a microflora edáfica, favorecendo seu estabelecimento na região da rizosfera (JAEGER et al., 1999). Marschner e Baumannn (2003) sugerem que as mudanças na estrutura da comunidade bacteriana podem ser, ao menos em parte, devido às mudanças na liberação de exsudatos pelas raízes de acordo com a idade da planta. De modo geral, a compatibilidade funcional na rizosfera é pouco conhecida requerendo mais estudos.

Tabela 3. Valor de pH final e concentração de $\mathrm{P}$ solúvel em meio líquido inoculado com fungos solubilizadores de fosfato e número de isolados obtidos da rizosfera de seis genótipos de guandu cultivados em amostras de seis classes de solo.

\begin{tabular}{|c|c|c|c|c|c|c|c|}
\hline \multirow[b]{2}{*}{ Genótipo } & \multicolumn{7}{|c|}{ Classes de Solo } \\
\hline & Luvissolo & Cambissolo & $\begin{array}{l}\text { Cambissolo } \\
\text { Eutrófico }\end{array}$ & $\begin{array}{l}\text { Argissolo } \\
\text { Vermelho } \\
\text { Amarelo }\end{array}$ & $\begin{array}{l}\text { Neossolo } \\
\text { Regolítico }\end{array}$ & Vertissolo & Média \\
\hline Moreilândia & $1,9(2 *)$ & $3,9(3)$ & $4,8(1)$ & $3,3(5)$ & $3,8(1)$ & $2,9(2)$ & $3,4(14)$ \\
\hline Seropédica & -- & -- & $2,6(1)$ & -- & $2,3(3)$ & -- & $2,5(4)$ \\
\hline CV208 & $2,8(2)$ & -- & $2,4(1)$ & $2,5(5)$ & $2,7(6)$ & $3,3(3)$ & $2,7(17)$ \\
\hline PPPI-1264 & $2,9(1)$ & $3,8(4)$ & $3,9(3)$ & $3,8(4)$ & $3,1(2)$ & $2,8(4)$ & $3,4(18)$ \\
\hline D1-Type & $2,5(2)$ & $2,4(3)$ & $3,4(9)$ & $2,8(2)$ & $4,6(1)$ & $3,3(2)$ & 3,2 (19) \\
\hline UW-10 & $2,6(1)$ & $2,9(5)$ & $2,7(2)$ & $2,4(2)$ & $3,4(1)$ & $2,6(2)$ & $2,8(13)$ \\
\hline Média & $2,5(8)$ & 3,3 (15) & 3,3 (17) & 2,9 (18) & 3,3 (14) & $3,0(13)$ & \\
\hline Moreilândia & 173 & 92 & 32 & 95 & 56 & 191 & 107 \\
\hline Seropédica & -- & -- & 217 & -- & 114 & -- & 166 \\
\hline CV208 & 153 & -- & 114 & 95 & 105 & 69 & 107 \\
\hline PPPI-1264 & 233 & 84 & 44 & 122 & 170 & 202 & 143 \\
\hline D1-Type & 96 & 108 & 114 & 43 & 40 & 96 & 83 \\
\hline UW-10 & 96 & 166 & 225 & 195 & 236 & 11 & 169 \\
\hline Média & 167 & 113 & 124 & 110 & 120 & 114 & \\
\hline
\end{tabular}

(*) número de isolados que originou a média

No caso dos genótipos Moreilândia e D1-Type, ambos foram trazidos de Petrolina, a mesma região de origem do Neossolo Regolítico. Provavelmente, existe uma melhor adaptação entre estes genótipos de guandu e as bactérias solubilizadoras daquela região, o que justificaria o maior número de bactérias obtido. Quanto às diluições de origem dos isolados de bactéria solubilizadora, foi verificada a seguinte distribuição: $8,28,8$ e 2 isolados originados das diluições $-3,-4,-5$ e -6 , respectivamente. Para os isolados fúngicos, esta distribuição foi de 19, 40, 18, 2, 4 e 2 isolados para as mesmas diluições acima 
citadas, respectivamente. Os isolados mais numerosos na rizosfera não foram necessariamente aqueles com maior capacidade de solubilização de fosfato. Os resultados de densidade populacional de solubilizadores geralmente são muito variáveis. Segundo Chabot, Antoun e Cescas (1993), estes microrganismos podem representar cerca de $50 \%$ da população da microbiota do solo. Entretanto, autores como Kucey (1983) descrevem uma população fúngica e bacteriana solubilizadora equivalente a apenas 0,1 e $0,5 \%$, respectivamente. De acordo com Silva Filho (1998) a população de microrganismos solubilizadores de fosfatos existente nos solos está entre $10^{4}$ e $10^{7} \mathrm{UFC}^{-1}$ de solo, variando conforme o local e método de avaliação.

Tabela 4. Valor de pH final e concentração de P solúvel em meio líquido inoculado com bactérias solubilizadoras de fosfato e número de isolados obtidos da rizosfera de seis genótipos de guandu cultivados em amostras de seis classes de solo.

\begin{tabular}{|c|c|c|c|c|c|c|c|}
\hline \multirow{3}{*}{ Genótipo } & \multicolumn{7}{|c|}{ Classes de Solo } \\
\hline & Luvissolo & Cambissolo & $\begin{array}{c}\text { Cambissolo } \\
\text { Eutrófico }\end{array}$ & $\begin{array}{l}\text { Argissolo } \\
\text { Vermelho } \\
\text { Amarelo }\end{array}$ & $\begin{array}{l}\text { Neossolo } \\
\text { Regolítico }\end{array}$ & Vertissolo & Média \\
\hline & \multicolumn{7}{|c|}{ - } \\
\hline Moreilândia & -- & $5,9(3 *)$ & -- & -- & $5,9(14)$ & $4,8(2)$ & $5,5(19)$ \\
\hline Seropédica & -- & -- & -- & $4,9(3)$ & $4,6(2)$ & -- & $4,8(5)$ \\
\hline CV208 & -- & -- & -- & $4,3(1)$ & -- & -- & $4,3(1)$ \\
\hline PPPI-1264 & -- & -- & -- & $4,1(5)$ & -- & -- & $4,1(5)$ \\
\hline D1-Type & -- & -- & $4,2(1)$ & -- & $6,0(10)$ & $6,2(2)$ & $5,5(13)$ \\
\hline UW-10 & -- & $4,8(1)$ & -- & -- & -- & $3,0(2)$ & $3,9(3)$ \\
\hline \multirow[t]{2}{*}{ Média } & -- & $5,4(4)$ & $4,2(1)$ & $4,4(9)$ & $5,5(26)$ & $4,7(6)$ & \\
\hline & \multicolumn{7}{|c|}{ 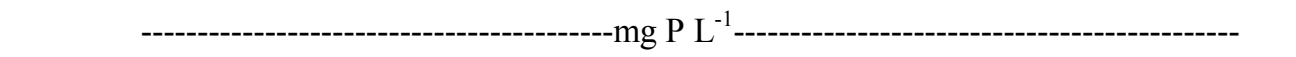 } \\
\hline Moreilândia & -- & 16 & -- & -- & 3 & 4 & 8 \\
\hline Seropédica & -- & -- & -- & 8 & 35 & -- & 22 \\
\hline CV208 & -- & -- & -- & 19 & -- & -- & 19 \\
\hline PPPI-1264 & -- & -- & -- & 26 & -- & -- & 26 \\
\hline D1-Type & -- & -- & 14 & -- & 17 & 3 & 11 \\
\hline UW-10 & -- & 4 & -- & -- & -- & 34 & 19 \\
\hline Média & -- & 10 & 14 & 18 & 28 & 14 & \\
\hline
\end{tabular}

(*) número de isolados que originou a média

Quantificação in vitro da solubilização biológica de fosfato

Não foi verificado nenhum efeito simples de genótipo ou classe de solo quanto aos valores de $\mathrm{pH}$ e $\mathrm{P}$ solúvel em meio líquido (Tabelas 3 e 4). Entretanto, houve determinadas combinações de solo e genótipo com maiores valores de P solúvel (Tabelas 3 e 4).

$\mathrm{O}$ controle apresentou valores iniciais de $\mathrm{pH}$ e $\mathrm{P}$ solúvel equivalente a 6,5 e $0,6 \mathrm{mg} \mathrm{L}^{-1}$, respectivamente. Verificou-se que a maioria dos fungos reduziu o $\mathrm{pH}$ para entre 2,0 e 4,0, enquanto que a maioria das bactérias reduziu-o para entre 4,0 e 6,5 .

Os fungos demonstraram crescimento mais abundante no meio líquido. Resultados semelhantes foram encontrados por Nahas, Centurion e Assis (1994), Illmer e Schinner (1995a), Illmer e Schinner (1995b) e Souchie et al. (2005b), que relatam maior capacidade de solubilização de fosfatos para os fungos comparados às bactérias, sendo isto, possivelmente, devido à maior produção de biomassa e redução de $\mathrm{pH}$. 
Houve uma relação inversa entre o pH do meio e a quantidade de P solúvel. Alguns isolados de fungo apresentaram valores fora da tendência geral observada para os demais isolados, com valores de pH abaixo de 2,0 e muitos deles elevaram os teores de $\mathrm{P}$ solúvel acima de $180 \mathrm{mg} \mathrm{L}^{-1}$. No caso das bactérias, apesar de alguns isolados apresentarem alto potencial de acidificação do meio, reduzindo o $\mathrm{pH}$ a valores equivalentes a 3,0, a maioria delas solubilizou o equivalente a apenas 1,8 e $9,0 \mathrm{mg}$ de $\mathrm{P}$ $\mathrm{L}^{-1}$. Dos 15 isolados fúngicos identificados, 14 pertenceram ao gênero Aspergillus e um ao gênero Penicillium. Estes resultados estão de acordo com Silva Filho, Narloch e Scharf (2002) que relatam estes dois gêneros de solubilizadores como os mais comumente descritos na literatura.

\section{Conclusões}

1. Determinadas combinações de solo e genótipo possibilitam maiores números de MSF e/ou maiores valores de $\mathrm{P}$ solúvel em meio líquido.

2. Os fungos apresentam maior potencial de solubilização de fosfato natural de Araxá que as bactérias.

3. Dentre os isolados de fungo identificados, o gênero Aspergillus predomina em relação ao gênero Penicillium.

\section{Agradecimentos}

Ao PRODETAB, pelo apoio financeiro e à Virgínia Tenório de Carvalho pelo auxílio em laboratório.

\section{Referências}

ABBOUD, A. C. S. Eficiência da adubação verde associada a fosfato natural de Patos de Minas. 1986. Dissertação (Mestrado em Agronomia - Ciência do Solo) - Universidade Federal Rural do Rio de Janeiro, Seropédica.
ASCENCIO, J. Growth strategies and utilization of phosphorus in Cajanus cajan L. Millsp. and Desmodium tortuosum (Sw.) DC under phosphorus deficiency. Communications in Soil Science and Plant Analysis, Georgia, v.27, n.5/8, p.1971-1993, 1996.

BARROTI, G.; NAHAS, E. População microbiana total e solubilizadora de fosfato em solo submetido a diferentes sistemas de cultivo. Pesquisa Agropecuária Brasileira, Brasília, v.35, n.10, p.2043-2050, 2000.

CARNEIRO, R. G.; MENDES, I. C.; LOVATO, P. E.; CARVALHO, A. M.; VIVALDI, L. J. Indicadores biológicos associados ao ciclo do fósforo em solos de cerrado sob plantio direto e plantio convencional. Pesquisa Agropecuária Brasileira, Brasília, v.39, n.7, p.661-669, 2004.

CHABOT, R.; ANTOUN, H.; CESCAS, M. P. Stimulation de la croissance du mais et de la laitue romaine par des microorganismes dissolvant le phosphores inorganique. Canadian Journal of Microbiology, Ottawa, v.39, p.941947, 1993.

ILLMER, P.; SCHINNER, F. Solubilization of hardly-soluble $\mathrm{AlPO}_{4}$ with P-solubilizing microorganisms. Soil Biology and Biochemistry, Oxford, v.27, n.3, p.265-270, 1995a.

ILLMER, P.; SCHINNER, F. Solubilization of inorganic calcium phosphates - solubilization mechanisms. Soil Biology and Biochemistry, Oxford, v.27, n.3, p.257-263, 1995b.

JAEGER, C. H.; LINDOW, S. E.; MILLER, W.; CLARK, E.; FIRESTONE, M. K. Mapping of sugar and amino acid availability in soil around roots with bacterial sensors of sucrose and tryptophan. Applied and Environmental Microbiology, Washington, v.65, n.6, p.2685-2690, 1999.

KANG, S. C.; HA, C. G.; LEE, T. G.; MAHESHWARI, D. K. Solubilization of insoluble inorganic phosphates by a soilinhabiting fungus Fomitopsis sp. PS 102. Current Science. Bangalore, v.82, n 4, p.439-442, 2002.

KIRCHNER, M. J.; WOLLUM, H. A. J.; KING, L. D. Soil microbial populations and activities in reduced chemical input agroecosystems. Soil Science of America Journal, Madison, v.57, n.5, p.1289-1295, sep./oct. 1993.

KUCEY, R. M. N. Phosphate-solubilizing bacteria and fungi in various cultivated and virgin Alberta soils. Canadian Journal of Soil Science, Ottawa, v.63, n.4, p.671-678, 1983.

KUMAR, V.; BEHL, R. K.; NARULA, N. Establishment of phosphate-solubilizing strains of Azotobacter chroococcum in the rhizosphere and their effect on wheat cultivars under greenhouse conditions. Microbiological Research, London, v.156, n.1, p.87-93, 2001. 
LIEBERSBACH, H.; STEINGROBE, B.; CLAASSEN, N. Roots regulate ion transport in the rhizosphere to counteract reduced mobility in dry soil. Plant and Soil, Dordrecht, v.10, n.1/2, p.79-88, mar. 2004.

MARSCHNER, P.; BAUMANN, K. Changes in bacterial community structure induced by mycorrhizal colonization in split-root maize. Plant and Soil, Dordrecht, v.251, p.279$289,2003$.

NAHAS, E.; CENTURION, J. F.; ASSIS, L. C. Microrganismos solubilizadores de fosfato e produtores de fosfatases de vários solos. Revista Brasileira de Ciência do Solo, Viçosa, v.18, p.43-48, 1994.

OTANI, T.; AE, N.; TANAKA, H. Phosphorus (P) uptake mechanisms of crop grown in soils with low $\mathrm{P}$ status. 2. Significance of organic acids in root exudates of pigeonpea. Soil Science and Plant Nutrition, Tokyo, v.42, n.3, p.553-560, 1996.

SAHIN, F.; ÇAKMAKÇI, R.; KANTAR, F. Sugar beet and barley yields in relation to inoculation with $\mathrm{N}_{2}$-fixing and phosphate solubilizing bacteria. Plant and Soil, Dordrecht, v.265, n.1-2, p.123-129, 2004.

SARAPATKA, B.; KRSKOVA, M. Interactions between phosphatase activity and soil characteristics from some locations in the Czech Republic. Rostlinna Vyroba, Praha, v.43, n.9, p.415-419, 1997.

SILVA, F. B. R.; SILVA, F. H. B. B.; CAVALCANTI, A. C.; SILVA, F. H. B. B.; BURGOS, N.; ARAÚJO FILHO, J. C. Guia de excursão de estudos de solos nos estados de Pernambuco, Paraíba, Rio Grande do Norte, Ceará e Bahia. In: REUNIÃO DE CLASSIFICAÇÃO, CORRELAÇÃO E APLICAÇÃO DE LEVANTAMENTOS DE SOLO, 5., 1998, Rio de Janeiro. Anais... Rio de Janeiro: Embrapa Solos, 1998.
SILVA FILHO, G. N. Solubilização de fosfatos pela microbiota do solo. 1998. Tese. (Doutorado em Agronomia - Ciência do Solo) - Universidade Federal do Rio Grande do Sul, Porto Alegre.

SILVA FILHO, G. N.; NARLOCH, C.; SCHARF, R. Solubilização de fosfatos naturais por microrganismos isolados de cultivos de Pinus e Eucalyptus de Santa Catarina. Pesquisa Agropecuária Brasileira, Brasília, v.37, n.6, p.847-854, 2002.

SINGH, K.; FRISVAD, J. C.; THRANE, U.; MATHUR, S. B. An illustrated manual on identification of some seedborne Aspergilli, Fusaria, Penicillia and their mycotoxins. Lyngby: Institute of Seed Pathology for Developing Countries, 1991.

SOUCHIE, E. L.; AZCÓN, R.; BAREA, J. M.; SAGGINJÚNIOR, O. J.; SILVA, E. M. R. Solubilização de fosfatos em meios sólido e líquido por bactérias e fungos do solo. Pesquisa Agropecuária Brasileira, Brasília, v.40, n.11, p.1149-1152, 2005 b.

SOUCHIE, E. L.; CAMPELLO, E. F. C.; SAGGIN-JÚNIOR, O. J.; SILVA, E. M. R. Mudas de espécies arbóreas inoculadas com bactérias solubilizadores de fosfato e fungos micorrízicos arbusculares. Floresta, Curitiba, v.35, n.2, p.329-334, 2005a.

SYLVESTER-BRADLEY, R.; ASAKAWA, N.; LATORRACA, S.; MAGALHÃES, F. M. M.; OLIVEIRA, L. A.; PEREIRA, R. M. Levantamento quantitativo de microrganismos solubilizadores de fosfato na rizosfera de gramíneas e leguminosas forrageiras na amazônia. Acta Amazônica, Manaus, v.1, p.12-22, 1982.

TEDESCO, M. J.; GIANELLO, C.; BISSANI, C. A.; BOHNEN, H.; VOLKWEISS, S. J. Análises de solo, plantas e outros materiais. 3.ed. Porto Alegre: Universidade Federal do Rio Grande do Sul, 1995. 